\title{
Characterization of the Gene Expression Profile of Human Hippocampus in Mesial Temporal Lobe Epilepsy with Hippocampal Sclerosis
}

\author{
Julio Lachos, ${ }^{1,2,3}$ Michela Zattoni, ${ }^{1}$ Heinz-Gregor Wieser, ${ }^{3}$ \\ Jean-Marc Fritschy, ${ }^{4}$ Thomas Langmann, ${ }^{5}$ Gerd Schmitz, ${ }^{5}$ Mariella Errede, ${ }^{6}$ \\ Daniela Virgintino, ${ }^{6}$ Yasuhiro Yonekawa, ${ }^{1}$ and Karl Frei ${ }^{1}$ \\ ${ }^{1}$ Department of Neurosurgery, University Hospital Zurich, 8091 Zurich, Switzerland \\ ${ }^{2}$ Department of Neurology, University Hospital Zurich, 8091 Zurich, Switzerland \\ ${ }^{3}$ Department of Psychiatry, University Hospital Zurich, Culmannstrasse 8, 8091 Zurich, Switzerland \\ ${ }^{4}$ Institute of Pharmacology and Toxicology, University of Zurich, 8057 Zurich, Switzerland \\ ${ }^{5}$ Institute for Clinical Chemistry, University of Regensburg, 93040 Regensburg, Germany \\ ${ }^{6}$ Department of Human Anatomy and Histology, Medical School, Bari University, 70124 Bari, Italy \\ Correspondence should be addressed to Julio Lachos, julio.lachos@usz.ch
}

Received 2 September 2010; Revised 10 December 2010; Accepted 1 January 2011

Academic Editor: Giangennaro Coppola

Copyright () 2011 Julio Lachos et al. This is an open access article distributed under the Creative Commons Attribution License, which permits unrestricted use, distribution, and reproduction in any medium, provided the original work is properly cited.

One of the main putative causes of therapy refractory epilepsy in mesial temporal lobe epilepsy (MTLE) with hippocampal sclerosis is the overexpression of multidrug transporters (MDTs) at the blood-brain barrier (BBB). It steps up the removal of antiepileptic drugs (AEDs) out of the brain cells across the BBB resulting in a low concentration of AEDs within the target cells. Some of the mechanisms of AED resistance are most likely to be genetically determined. To obtain more information about the underlying pathophysiology of intractability in epilepsy, we compared the global gene expression profile of human hippocampus and hippocampal-derived microvascular endothelial cells from MTLE with HS patients and controls. At the level of MDT, a significant up-regulation was found for $\mathrm{ABCB} 1$ (P-gp), $\mathrm{ABCB} 2, \mathrm{ABCB} 3$, and $\mathrm{ABCB} 4$, which was mainly related to endothelial cells. The data on the MDT were validated and extended by quantitative RT-PCR. Surprisingly, inflammatory factors such as interleukins (IL- $1 \alpha$, IL-1 $\beta$, IL-6, and IL-18) and cytokines (TNF- $\alpha$ and TGF- $\beta 1$ ) were found to be up-regulated in hippocampal parenchyma. The overexpression of P-gp, IL-1 $\beta$, and IL-6 was also confirmed by immunohistochemistry (IHC). Our results suggest that complex expression changes of ABC-transporters may play a decisive role in pharmacoresistance in MTLE. Further studies on the new and unexpected overexpression of inflammatory cytokines may unlock hitherto undiscovered pathways of the underlying pathophysiology of human MTLE.

\section{Introduction}

Mesial temporal lobe epilepsy (MTLE) with hippocampal sclerosis (HS) is the most common type of epilepsy in adults [1]. HS consists of gliosis, neuronal loss and cell dispersion. As many as $75 \%$ of the patients with MTLE are considered to be resistant to drug therapy with AEDs. Pharmacoresistance is a common problem in neurological and psychiatric disorders which leads to a big distress among patients and family members. The long-term followup after selective amygdalohippocampectomy (sAHE) in the presence of severe HS showed a greater than $80 \%$ of patients becoming seizure free [2]. The causes and mechanisms underlying drug resistance in MTLE are still badly understood, which hampers the development of new drugs and thus the availability of better treatment options [3-6]. The main factors which might contribute to the development of medically intractable MTLE are aetiology of epilepsy, the progression of seizure activity under drug therapy, changes in the targets of AEDs, abnormalities in 
the neuronal networks owing to damage in the epileptogenic focus during epileptogenesis, and changes in the druguptake across the BBB [7]. Genetic factors may explain why patients with the same type of epilepsy respond differently to the same drug therapy. In recent years, several putative mechanisms underlying drug resistance in epilepsy have been identified. One theory that has received considerable attention is the removal of AEDs from the epileptogenic tissue through overexpression of multidrug transporters at the BBB. This theory is biologically feasible and can partly explain drug-resistance. Although MTLE is usually not regarded as a neuroimmunological disease, proinflammatory cytokines and chemokines may play a role in seizure onset $[8,9]$. It has also been reported in experimental models of limbic seizures that there is a rapid and transient increase of IL- $1 \beta$, IL- 6 , and TNF- $\alpha$ mRNA in the hippocampus, and that intrahippocampal injection of IL- $1 \beta$ has a detrimental effect on seizures [10].

Furthermore, a polymorphism in the IL- $1 \beta$ gene has been associated with MTLE-HS compared to patients without sclerosis and nonepileptic controls $[11,12]$. Febrile seizures, particularly complex febrile seizures and status epilepticus during early childhood, have been associated with hippocampal sclerosis and overexpression of IL-1 $\beta$ [13]. The relevance of sclerotic hippocampus in seizure maintenance and therapy refractoriness has led to us to investigate the mRNA expression profile of the sclerotic hippocampus in order to obtain a comprehensive view of this particular pathology at the molecular level. Accordingly, we used a DNA microarray approach. The main aim of this study was to identify those genes which may be involved in the pathogenesis of MTLE-HS. A separate comparison was performed for mRNAs extracted from the entire tissue and from MVECs prepared from the resected tissue.

In the interpretation and discussion of the data, we focused on the multidrug-transporter overexpression theory and on the genes which were found to be among the most overexpressed in sclerotic hippocampus.

\section{Methods}

2.1. Surgical Specimens. Clinical specimens were obtained from ten caucasian patients with chronic pharmaco-resistant MTLE, who underwent surgical treatment at the Department of Neurosurgery, University Hospital Zurich (Table 1). Surgical removal of the hippocampus was clinically indicated in every case. The specimen was obtained by selective amygdalohippocampectomy (sAHE). With this surgical approach, parts of the amygdala, the hippocampus, and the anterior portion of the parahippocampal gyrus (Gph) are selectively removed. All tissues were diagnosed by two pathologists at the Department of Neuropathology, University Hospital Zurich. The hippocampus and the Gph were examined and separately rated for the presence and severity of hippocampal sclerosis (HS) based on the extent of gliosis and neuronal loss (mild, marked, and severe). All hippocampal regions revealed HS with various degrees of gliosis and neuronal loss. All analyses were conducted in accordance with the Declaration of Helsinki and approved by the Ethics Committee of the Canton of Zurich. Informed written consent was obtained from all patients. Control human brain hippocampus total RNA were commercially purchased by Ambion (Ambion, Inc. Texas, USA). The autopsy controls $(n=3 ; 45$, $5 \pm 10$ years old; 2 female, 1 male; Caucasians) had no history of brain-related disease and suffered sudden death without associated brain damage. Autopsy was rapidly performed with a short postmortem delay. Autopsy hippocampi were dissected and immediately collected in RNA-Later tubes and frozen until processing. Totally RNA was isolated using the modified version of Ambion's RNA KIT for RNA-Isolation, and RNA was stored in $1 \mathrm{mM}$ sodium citrate $(\mathrm{pH} 6.4)$ at $-70^{\circ}$.

\subsection{Isolation of Human Brain-Derived Microvascular Endo-} thelial Cells (MVECs). MVECs were isolated as described by $[14,15]$. Briefly, ependym, large vessels and pia membrane were dissected away with the help of a microscope, and the remaining tissue minced and homogenized with a $10 \mathrm{~mL}$ syringe in $10 \mathrm{~mL}$ MCDB 131 medium (Gibco, Invitrogen, Basel, Switzerland), containing 2\% FBS (PAA Laboratories, Linz, Austria), 16 U/mL heparin (Sigma, Fluka Chemie, AG Buchs, Switzerland), $20 \mu \mathrm{L}$ BBE, $5 \mu \mathrm{L}$ hEGF, $5 \mu \mathrm{L}$ hydrocortisone, $5 \mu \mathrm{L}$ FGF (all from Cell System Inc. Kirkland. WA), $50 \mu \mathrm{L}$ ECGS (Serva, Heidelberg, Germany), $500 \mu \mathrm{L}$ gentamicin (Sigma). The tissue was dissociated in a glass flask in dispase II solution (Roche, Rotkreuz, Switzerland) at a final concentration of $0.096 \mathrm{U} / \mathrm{mL}$ and the solution was placed in a water bath at $37^{\circ} \mathrm{C}$ and stirred for approximately 1 hour. The homogenate was centrifuged $(1,000 \times \mathrm{g}, 10 \mathrm{~min}$, $4^{\circ} \mathrm{C}$ ) and the supernatant was removed. The pellet was dissolved in 2 mL MCDB 131 medium, containing 20\% dextran, (Sigma) and gently homogenized with a fire-polished pipette and centrifuged $\left(1,700 \times \mathrm{g}, 10 \mathrm{~min}, 4^{\circ} \mathrm{C}\right)$. The top layer containing most of the myelin was discarded. The pellet was resuspended in MCDB 131, containing 2\% FBS medium, layered on $2 \mathrm{~mL} \mathrm{13 \%}$ dextran, and again centrifuged $(1,700 \times \mathrm{g}$, $10 \mathrm{~min}, 4^{\circ} \mathrm{C}$ ) to remove the remaining myelin. The pellet was solubilized in $1 \mathrm{mg} / \mathrm{mL}$ collagenase/dispase (Roche) and $0.05 \mathrm{mg} / \mathrm{mL}$ DNase I (Sigma) and stirred for 1 hour. The cells were pelleted $\left(380 \times \mathrm{g}, 10 \mathrm{~min}, 4^{\circ} \mathrm{C}\right)$ and washed with MCDB 131 containing $2 \%$ FBS medium, and the pellet was finally placed in $1 \mathrm{~mL}$ QIAzol lysis reagent (Qiagen, Basel, Switzerland) frozen and kept at $-70^{\circ} \mathrm{C}$ until further processing.

2.3. Processing of Hippocampal Tissues. Immediately after surgery hippocampal specimen from epileptic patients were stored in RNAlater stabilization reagents (Qiagen) in order to prevent degradation of RNA. The samples were stored at $4^{\circ} \mathrm{C}$ overnight and subsequently frozen and kept at $-70^{\circ} \mathrm{C}$ until further processing.

2.4. Isolation and Analysis of RNA. Total RNA from isolated MVEC was extracted by using QIAzol lysis reagent according to the manufacturer's protocol. The isolated MVECs were placed in $1 \mathrm{~mL}$ QIAzol reagent, frozen and kept at $-70^{\circ} \mathrm{C}$. After thawing, $0.2 \mathrm{~mL}$ dichloromethane was added and the samples were centrifuged $\left(12,000 \mathrm{~g}, 15 \mathrm{~min}, 4^{\circ} \mathrm{C}\right)$ for phase 


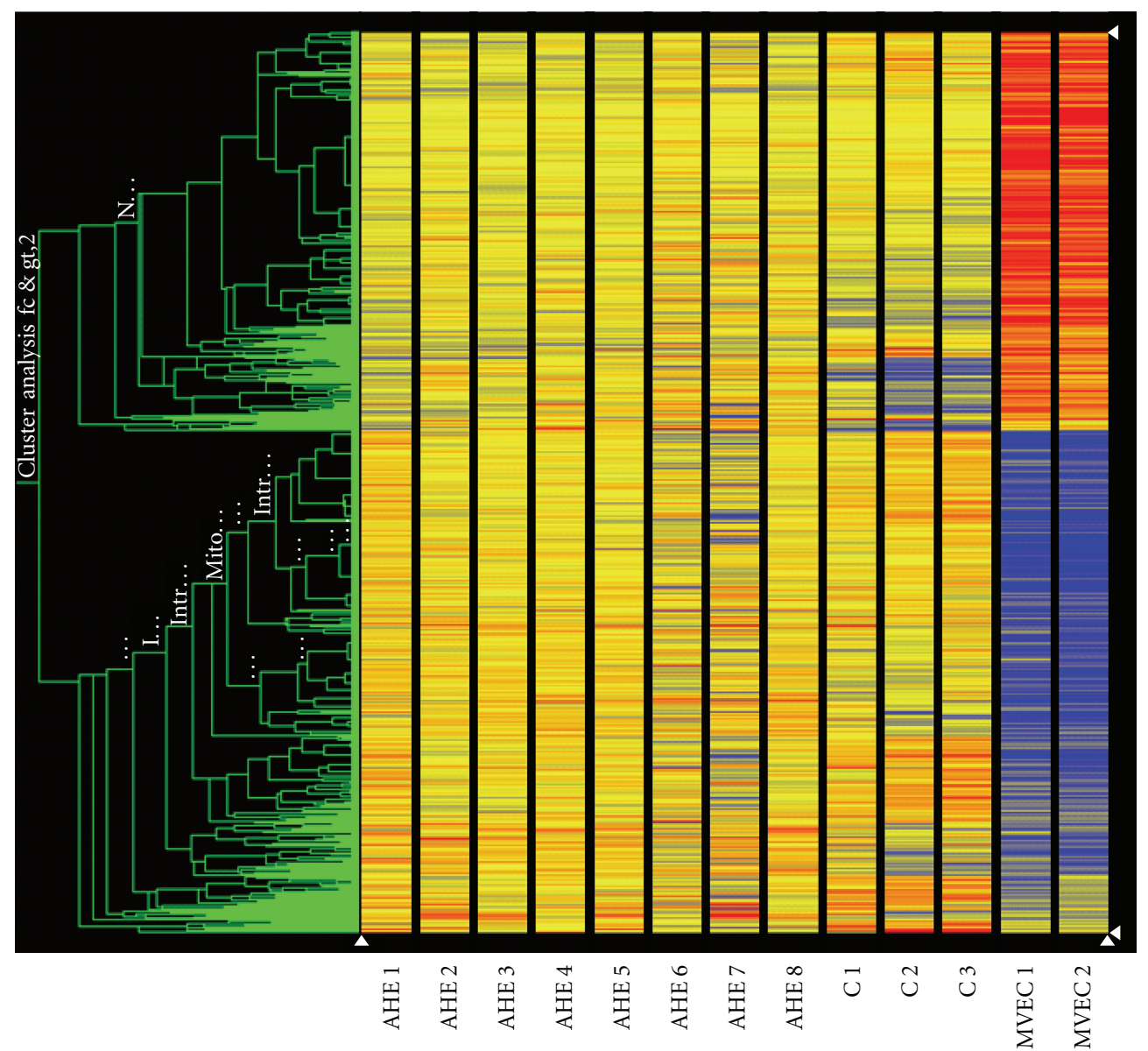

Figure 1: Cluster analysis of the gene expression patterns of isolated MVECs $(n=2)$ and AHEs $(n=8)$ from patients with MTLE after selective amygdalohippocampectomy (sAHE) and control hippocampal tissue specimens $(n=3)$. The analysis was performed using GeneSpring software. The analysis included all differentially expressed genes expressed in oligonucleotide microarray analysis (Affymetrix, HG-U133Plus2.0). Each horizontal colour bar denotes the intensity of expression of a particular gene in a distinct sample relative to the mean expression value of all samples. Yellow denotes little or no change, red denotes increased expression, and blue denotes decreased expression. AHE: amygdalohippocampectomy, MVEC: microvascular endothelial cells, and C: control.

separation. The RNA from the upper aqueous phase was precipitated by mixing with $0.5 \mathrm{~mL}$ isopropyl alcohol. After 10 min incubation the samples were centrifuged $(12,000 \times \mathrm{g}$, $10 \mathrm{~min}, 4^{\circ} \mathrm{C}$ ) and the RNA pellet was washed with $1 \mathrm{~mL}$ $75 \%$ ethanol. At the end of the procedure, the RNA was briefly dried and then dissolved in RNase-free water. The hippocampal biopsies were thawed, placed in $1 \mathrm{~mL}$ QIAzol reagent for RNA isolation, and processed according to the protocol RNeasy Lipid Tissue Mini Handbook (Qiagen). The quality of the isolated RNA was determined by NanoDrop ND 1000 (NanoDrop Technologies, Delaware, USA) and a Bionalyser 2100 (Agilent Technologies, Basel, Switzerland). Only those samples with a $260 \mathrm{~nm} / 280 \mathrm{~nm}$ ratio between $1.8-2.1$ and a $28 \mathrm{~S} / 18 \mathrm{~S}$ ratio within $1.5-2$ were processed further and investigated. Control human hippocampal RNA was commercially purchased (Ambion Ltd., Huntingdon, UK).

2.5. cRNA Preparation. $3 \mu \mathrm{g}$ and $100 \mathrm{ng}$ of total RNA per sample were reverse-transcribed into double-stranded cDNA with one-cycle and two cycle cDNA synthesis kit (Affymetrix Inc., P/N 900431, Santa Clara, CA), respectively. The doublestranded cDNA was purified using a Sample Cleanup Module (Affymetrix Inc.). The purified double-stranded cDNA was in vitro transcribed (IVT) in the presence of biotinlabeled nucleotide using an IVT Labeling Kit (Affymetrix Inc.) and the biotinylated cRNA was purified using a Sample Cleanup Module (Affymetrix Inc., P/N 900371). The quality and quantity of biotin-labeled cRNA were determined using NanoDrop ND 1000 and Bioanalyzer 2100.

2.6. Array Hybridization. $15 \mu \mathrm{g}$ of biotin-labeled cRNA was fragmented randomly to $35-200 \mathrm{bp}$ at $94^{\circ} \mathrm{C}$ in fragmentation buffer (Affymetrix Inc., $\mathrm{P} / \mathrm{N}$ 900371) and were mixed in $300 \mu \mathrm{L}$ of hybridization buffer containing a hybridization control cRNA and control Oligo B2 control (Affymetrix Inc., P/N 900454), $0.1 \mathrm{mg} / \mathrm{mL}$ herring sperm DNA, and $0.5 \mathrm{mg} / \mathrm{mL}$ acetylated bovine serum albumin in 2-(4-morpholino)-ethane sulfonic acid (MES) buffer, $\mathrm{pH}$ 6.7, before hybridization to GeneChip Human Genome 
TABle 1: Clinical history, MRI findings, pathological diagnosis, and postoperative outcome of 10 patients who underwent selective amygdalohippocampectomy.

\begin{tabular}{|c|c|c|c|c|c|c|c|}
\hline $\begin{array}{l}\text { Case } \\
\text { no. }\end{array}$ & Age/sex & $\begin{array}{l}\text { MRI } \\
\text { findings }\end{array}$ & Pathological diagnosis of hippocampus & $\begin{array}{c}\text { AED } \\
\text { medication }\end{array}$ & $\begin{array}{l}\text { Type of } \\
\text { seizures }\end{array}$ & Years with epilepsy & No. seizures/month \\
\hline $1^{\mathrm{a}, \mathrm{b}, \mathrm{c}}$ & $21 / \mathrm{M}$ & MTS, left & mild gliosis, focal neuronal loss & LTG, LEV & SPS, CPS & 19 & 30 \\
\hline $2^{a, b, c}$ & $26 / \mathrm{F}$ & MTS, right & mild gliosis, severe neuronal loss & $\begin{array}{l}\text { CBZ, GP, } \\
\text { LEV }\end{array}$ & CPS, SGS & 10 & 8 \\
\hline $3^{\mathrm{a}, \mathrm{b}, \mathrm{c}}$ & $28 / \mathrm{F}$ & MTS, left & $\begin{array}{l}\text { marked gliosis, severe neuronal loss } \\
(\text { Wyler II })^{\mathrm{f}}\end{array}$ & $\begin{array}{l}\text { OXC, LTG, } \\
\text { PHT }\end{array}$ & $\begin{array}{l}\text { SPS, CPS, } \\
\text { SGS }\end{array}$ & 26 & 2 \\
\hline $4^{\mathrm{a}, \mathrm{b}, \mathrm{c}}$ & $27 / \mathrm{M}$ & MTS, right & $\begin{array}{l}\text { marked gliosis, severe neuronal loss } \\
\text { (Wyler II) }\end{array}$ & LTG, LEV & CPS, SGS & 25 & 4 \\
\hline $5^{\mathrm{a}, \mathrm{b}, \mathrm{c}}$ & $34 / \mathrm{F}$ & MTS, left & $\begin{array}{l}\text { marked gliosis, severe neuronal loss } \\
\text { (Wyler III) }\end{array}$ & LEV, PB & $\begin{array}{l}\text { SPS, CPS, } \\
\text { SGS }\end{array}$ & 32 & 6 \\
\hline $6^{\mathrm{b}, \mathrm{c}}$ & $40 / \mathrm{F}$ & MTS, left & marked gliosis, focal mild neuronal loss & VPA, LEV & CPS, SGS & 18 & 12 \\
\hline $7^{b, c}$ & $68 / \mathrm{F}$ & MTS, right & marked gliosis, severe neuronal loss & LTG, LEV & SPS, CPS & 43 & 4 \\
\hline $8^{b, c}$ & $22 / \mathrm{M}$ & MTS, right & $\begin{array}{l}\text { marked gliosis, severe neuronal loss } \\
\text { (Wyler IV) }\end{array}$ & $\begin{array}{l}\text { CBZ, GP, } \\
\text { LEV }\end{array}$ & $\begin{array}{l}\text { SPS, CPS, } \\
\text { SGS }\end{array}$ & 18 & 4 \\
\hline $9^{\mathrm{d}, \mathrm{e}}$ & $41 / \mathrm{M}$ & MTS, right & $\begin{array}{l}\text { marked gliosis, severe neuronal loss } \\
\text { (Wyler IV) }\end{array}$ & $\begin{array}{l}\text { CBZ, VPA, } \\
\text { TPM }\end{array}$ & $\begin{array}{l}\text { SPS, CPS, } \\
\text { SGS }\end{array}$ & 6 & 2 \\
\hline $10^{\mathrm{d}, \mathrm{e}}$ & $41 / \mathrm{F}$ & MTS, left & marked gliosis, severe neuronal loss & $\begin{array}{l}\text { CBZ, LEV, } \\
\text { PHT }\end{array}$ & $\begin{array}{l}\text { SPS, CPS, } \\
\text { SGS }\end{array}$ & 20 & 2 \\
\hline
\end{tabular}

AEDs: antiepileptic drugs; CBZ: carbamazepine; LEV: levetiracetam; LTG: lamotrigine; PHT: phenytoin; TPM: topiramate; GP: gabapentin; PB: phenobarbital; OXC: oxcarbazepine; VPA: valproic acid.

SPS: simple partial seizures; CPS: complex partial seizures; SGS: secondary generalized seizures.

${ }^{\mathrm{a}}$ Immunohistochemistry.

${ }^{\mathrm{b}}$ One-cycle target labelling gene array.

${ }^{\mathrm{c}}$ Quantitative real-time RT-PCR (TaqMan).

${ }^{\mathrm{d} B r a i n}$-derived microvascular endothelial cells (MVECs).

${ }^{\mathrm{e}}$ Two-cycle target labeling gene array.

${ }^{\mathrm{f}}$ Wyler classification was not determined in all cases.

MTS, mesial temporal sclerosis.

TABLE 2: Averaged relative gene expression values of AHE, MVEC, and control of the ATP-binding cassette (ABCB1, $A B C B 2, A B C B 3$, and ABCC4).

\begin{tabular}{|c|c|c|c|c|}
\hline Genes & Symbol & Control $^{\mathrm{a}}$ & $\mathrm{AHE}^{\mathrm{a}}$ & MVEC $^{\mathrm{a}}$ \\
\hline ATP-binding cassette, sub-family B (MDR/TAP), member 1 & ABCB1/P-gp & $1 \pm 0.03$ & $0.91 \pm 0.24$ & $\begin{array}{l}37.22 \pm 0.97 \\
(P=.0003)^{b}\end{array}$ \\
\hline Transporter 1, ATP-binding cassette, sub-family B (MDR/TAP) & ABCB2/TAP1 & $1 \pm 0.19$ & $1.13 \pm 0.33$ & $\begin{array}{c}21.08 \pm 2.82 \\
(P=.0017)\end{array}$ \\
\hline Transporter 2, ATP-binding cassette, sub-family B (MDR/TAP) & ABCB3/TAP2 & $1 \pm 0.11$ & $1.14 \pm 0.27$ & $\begin{array}{c}13.39 \pm 6.08 \\
(P=.0012)\end{array}$ \\
\hline ATP-binding cassette, sub-family C (CFTR/MRP), member 4 & ABCC4/MRP4 & $1 \pm 0.07$ & $\begin{array}{c}2.13 \pm 0.68 \\
(P=.001)\end{array}$ & $\begin{array}{c}5.39 \pm 2.44) \\
(P=.005)\end{array}$ \\
\hline
\end{tabular}

${ }^{a}$ Fold changes were calculated on the bases of normalized values calculated by Genespring 5.0. The mean values of the three controls were set to the value of 1. The data are presented as a mean $\pm \mathrm{SD}$.

${ }^{\mathrm{b}}$ The statistical differences in comparison to control are indicated ( $P$-value, Student's $t$-Test).

U133Plus2.0 arrays, which contains 47,000 transcripts, for 16 hours at $45^{\circ} \mathrm{C}$. Arrays were then washed using an Affymetrix Fluidics Station 450 EukGE-WS2v5_450. Affymetrix GeneChip Scanner 3000 (Affymetrix Inc.) was used to measure the fluorescent intensity emitted by the labeled target.

2.7. Microarray Data Analysis. Raw data processing was performed using the Affymetrix Genespring software (Silicon Genetics, California, USA). After hybridization and scanning, probe cell intensities were calculated and summarized for the respective probe sets by means of the MAS5 algorithm [16]. To compare the expression values of the genes from chip to chip, global scaling was performed, which resulted in the normalization of the trimmed mean of each chip to target intensity (TGT value) of 500 as detailed in the statistical algorithms description document of Affymetrix. Quality control measures were considered before performing the statistical analysis. These included adequate scaling factors (between 1 and 3 for all samples) and appropriate numbers of present calls calculated by application of an algorithm. The efficiency of the labelling reaction and the hybridization 
TABLE 3: Comparison of the averaged values of individual epileptic patients and controls between microarray and RT-PCR analysis for genes, which are suspected to be involved in medically intractable epilepsy.

\begin{tabular}{|c|c|c|c|c|c|}
\hline \multirow[b]{2}{*}{ Genes } & \multirow[b]{2}{*}{ Symbol } & \multicolumn{2}{|c|}{ Gene array $^{1}$} & \multicolumn{2}{|c|}{ RT-PCR ${ }^{2}[\text { Ct values }]^{3}$} \\
\hline & & Control & AHE & Control & AHE \\
\hline $\begin{array}{l}\text { ATP-binding cassette, sub-family B } \\
\text { (MDR1/TAP), member } 1\end{array}$ & ABCB1/P-gp & $136.3 \pm 26.2$ & $\begin{array}{l}164.3 \pm 60.5 \\
(P=.469)^{*}\end{array}$ & $1.2 \pm 0.1[30.1 \pm 0.6]$ & $\begin{array}{c}2.3 \pm 0.5(P=.030) \\
{[28.3 \pm 0.6]}\end{array}$ \\
\hline $\begin{array}{l}\text { Transporter 1, ATP-binding cassette, } \\
\text { sub-family B (MDR/TAP) }\end{array}$ & ABCB2/TAP1 & $58.7 \pm 12.3$ & $\begin{array}{l}97.8 \pm 15.2 \\
(P=.251)\end{array}$ & $0.9 \pm 0.1[31.9 \pm 0.5]$ & $\begin{array}{c}2.1 \pm 0.8(P=.020) \\
{[29.7 \pm 0.8]}\end{array}$ \\
\hline $\begin{array}{l}\text { Transporter 2, ATP-binding cassette, } \\
\text { subfamily B (MDR/TAP) }\end{array}$ & ABCB3/TAP2 & $42.3 \pm 9.6$ & $\begin{array}{l}67.9 \pm 12.5 \\
(P=.163)\end{array}$ & $1.1 \pm 0.2[32.8 \pm 0.9]$ & $\begin{array}{c}2.1 \pm 0.8(P=.023) \\
{[30.1 \pm 1.0]}\end{array}$ \\
\hline $\begin{array}{l}\text { ATP-binding cassette, sub-family C } \\
\text { (CFTR/MRP), member } 4\end{array}$ & ABCC4/MRP4 & $104.7 \pm 7.2$ & $\begin{array}{c}235.0 \pm 69.4 \\
(P=.012)\end{array}$ & $1.2 \pm 0.2[31.1 \pm 0.5]$ & $\begin{array}{c}6.4 \pm 2.1(P=.030) \\
{[28.7 \pm 0.7]}\end{array}$ \\
\hline
\end{tabular}

${ }^{1}$ The microarray data are presented as raw values calculated by Microarray Suite 5. The data are given as means \pm SD of three controls and eight epileptic patients for each gene, respectively.

${ }^{2}$ The results of RT-PCR analysis are expressed as relative gene expression and normalized with $18 \mathrm{~S}$ rRNA expression as reference gene.

Data are presented as mean \pm SD of three controls. ${ }^{*}$ The statistical differences between AHE and controls are indicated ( $P$-value, Student's $t$-Test).

${ }^{3}$ Threshold cycles [CT-values] are given as mean $\pm \mathrm{SD}$

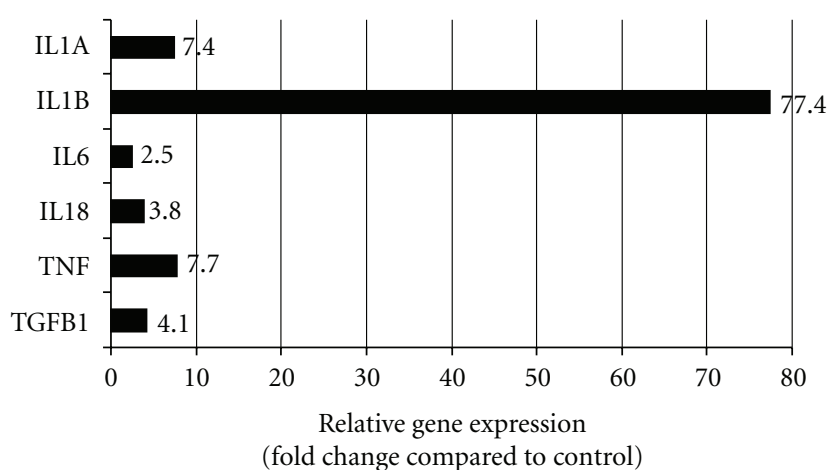

FIGURE 2: Relative gene expression of IL- $1 \alpha$, IL-1 $\beta$, IL-6, IL-18, TNF- $\alpha$, and TGF- $\beta 1$ of control hippocampal tissues $(n=3)$ and AHEs $(n=8)$. The results of gene array analysis were calculated by GeneSpring software. Control mean values were set to one and the fold change of the AHE means calculated.

performance was controlled with the following parameters: present calls and optimal 3//5' hybridization ratios (around 1) for the housekeeping genes (GAPDH and ACO7), for the poly A spike in controls and the prokaryotic control (BIOB, BIOC, CREX, BIODN). Analysis was performed by setting controls sample data set to zero and filtering and utilizing only genes with transcripts flagged "present" or "marginal". Gene transcripts with a difference of 2-fold or greater "induction" or "reduction" when compared to controls were subsequently annotated and grouped according to their molecular and cellular function.

\subsection{Quantitative Real-Time Reverse Transcription-Polymerase} Chain Reaction (RT-PCR). Total RNA was extracted from hippocampal biopsies and MVEC using QIAzol reagent (Qiagen) according to the manufacturer's protocol. Quantification of $\mathrm{ABC}$ transporters was performed by a TaqMan Low Density Array, which is based on an Applied Biosystems 7900HT Micro Fluid Card. The method allows simultaneous analysis of 47 human $\mathrm{ABC}$ transporters and the reference gene $18 \mathrm{~S}$ rRNA in two replicates of four different samples per run [17].

2.9. Immunohistochemistry and Immunofluorescence. The following antibodies were used for IHC MRP1 (MRP1), MRP2 (M2I-4), MRP3 (M3II-9), MRP4 (M4I-80), MRP5 (M5I-1), all from Alexis, Lausen, Switzerland and IL$1 \beta$ (ab2105) and IL-6 (ab6672), both from Abcam, UK. Hippocampal samples were fixed in formalin $4 \%$ and embedded in paraffin. Sections were cut at thickness of $2 \mu \mathrm{m}$, mounted on gelatinized glass-slides, deparaffinized, rehydrated, and rinsed (Tris puffer, $\mathrm{pH}=7.4$ ). The slides were pretreated for antigen retrieval in $10 \mathrm{mM} \mathrm{Na}$-citrate, $\mathrm{pH}$ 6, in microwave for $10 \mathrm{~min}$. Subsequently, sections were treated with $0.3 \% \mathrm{H}_{2} \mathrm{O}_{2}$ in methanol for $10 \mathrm{~min}$ to abolish endogenous peroxidase activity and with $2 \%$ normal goat serum in Tris for $20 \mathrm{~min}$ to block nonspecific igG binding sites. The primary antibody diluted in Tris $(1: 50)$ and applied overnight at $4^{\circ} \mathrm{C}$. After rinsing in Tris, the sections were incubated with biotin labelled antimouse $\operatorname{IgG}(1: 100)$ or antirat $\operatorname{IgG}(1: 100)$ for 1 hour at RT. After washing in Tris, the sections were incubated with biotin-avidin complex, containing peroxidase (Dako), and washed and stained with haematoxylin for nuclear staining, finally dehydrated and cleared in xylene and cover glass mounted with eukitt (ErneChemie, Switzerland).

Immunolabeling of MTLE tissue: $20-\mu \mathrm{m}$ sections were obtained using a vibrating microtome (VT 1000S, Leica, Heilderberg, Germany) and processed as free-floating sections for double immunolabeling with mouse anti-P-gp C494 (Signet Laboratories, Dedham, MA, diluted 1:10 to $1: 40$ in $\mathrm{BB}$ ) and rabbit anti-GFAP (diluted $1: 1$ in BB; prediluted antibody from ImmunoStar, Hudson, WI). The incubation steps were as follows: (1) $30 \mathrm{~min}$ in $\mathrm{BB},(2) 30$ minutes in $0.5 \%$ Triton X-100 in PBS, (3) 1 hour in a mixture of the primary antibodies at RT, and (4) 1 hour in the fluorophore conjugates goat antimouse and goat anti-rabbit IgGs at RT (diluted 1:200 in BB; Alexa Fluor 488 and 555, respectively; Invitrogen) at RT. The sections 


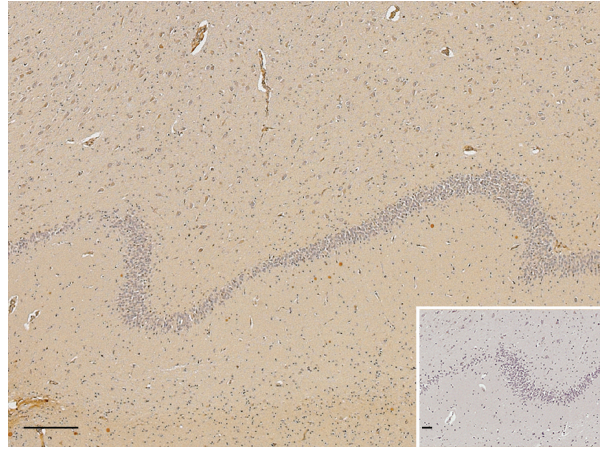

(a)

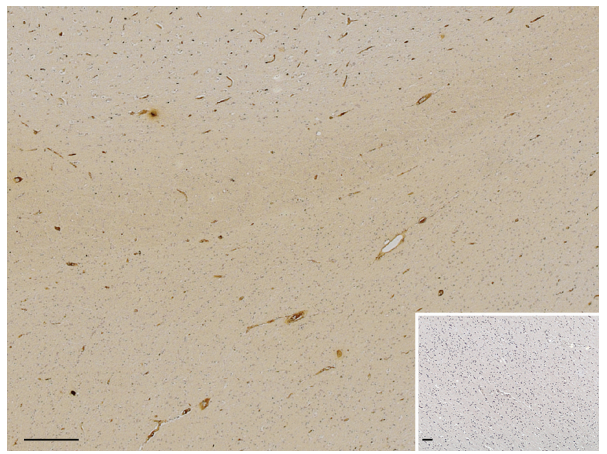

(c)

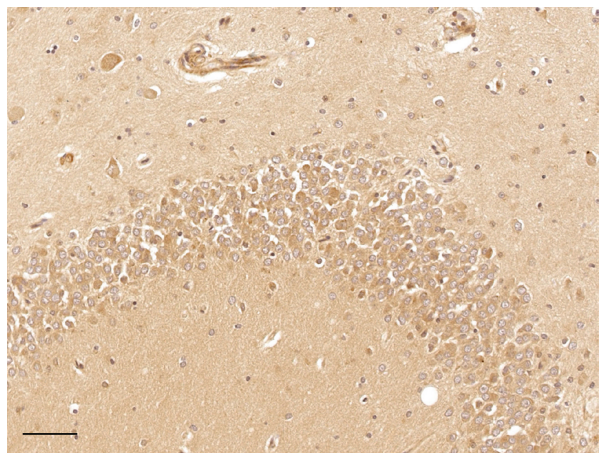

(e)

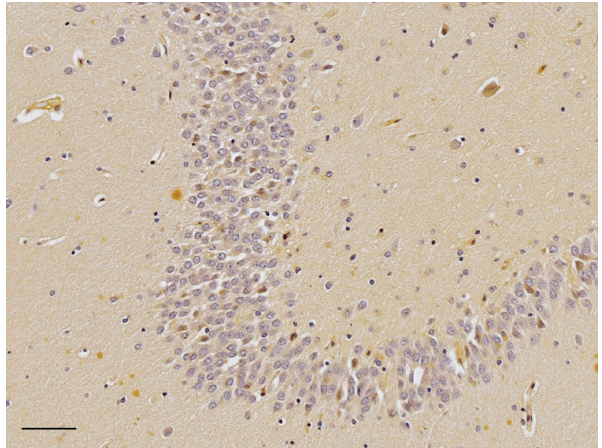

(b)

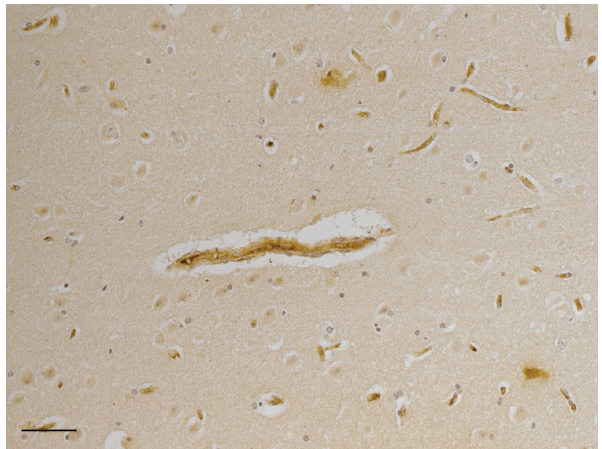

(d)

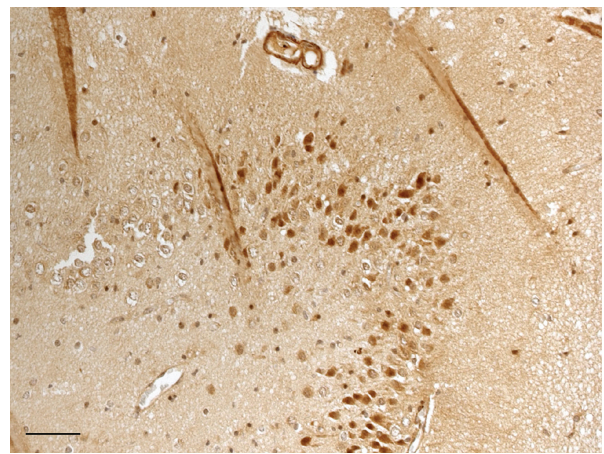

(f)

Figure 3: Photomicrographs of IL-1 $\beta(\mathrm{a}, \mathrm{b}, \mathrm{c}, \mathrm{d})$ and IL-6 (e, f) in hippocampus (dentate gyrus) from a control (a, b, e) and epileptic patient (no. 5) (c, d, f). Only a weak IL- $1 \beta$ staining was found in control patient $(a, b, e)$ in contrast to the epileptic patient (c, d, f). The staining was mainly confined to the neurovascular unit. Figures show transverse sections at different magnifications $(\mathrm{a}, \mathrm{c}, \mathrm{e}: \times 4$; b, $\mathrm{d}$ and f: $\times 20)$. Scale bar: $100 \mu \mathrm{m}$. Isotype antibody controls are shown as inserts in a and c.

were washed 3 times for $10 \mathrm{~min}$ in PBS between each step and counterstained with TOPRO-3 (diluted $1: 10,000$ in PBS; Invitrogen) added to the final wash. The sections were then transferred onto Vectabond treated slides (Vector Laboratories), carefully drained, coverslipped in Vectashield mounting medium (Vector Laboratories), and sealed with nail varnish.

\section{Results}

The GeneChip expression analysis was performed from control hippocampi $(n=3)$, hippocampal MTLE biopsies $(n=8)$, and isolated MVECs $(n=2)$ thereof. A total of 27,000 out of 54,000 mRNA transcripts of known or predicted function were found to be present in all samples. The expressed genes were normalized and compared with control. Gene transcripts with $>2$-fold induction or reduction were analyzed. The comparison of the gene expression profiles of AHEs, MVECs, and controls is shown in the multidimensional hierarchical cluster analysis (Figure 1). This analysis revealed remarkable differences between the three groups. When AHEs were compared with controls, a total of 1,253 genes were found to be significantly upregulated and 637 genes down-regulated. Among the many up-regulated genes we found also GFAP (7.6-fold) as a bona fide marker for astrogliosis. The comparison between MVEC 


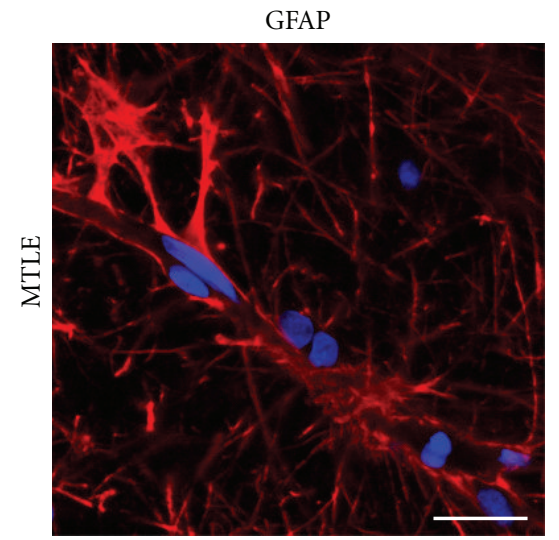

(a)

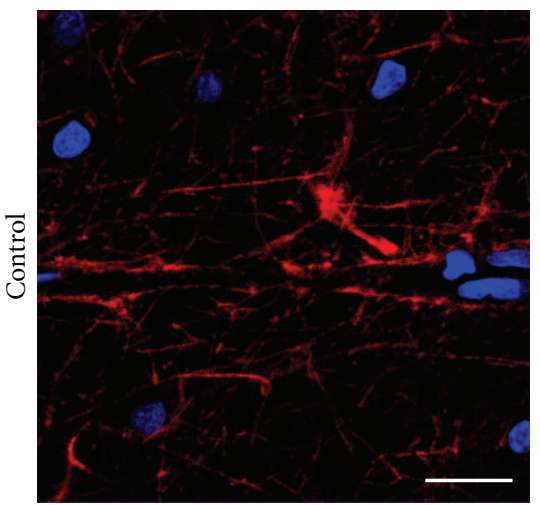

(d)

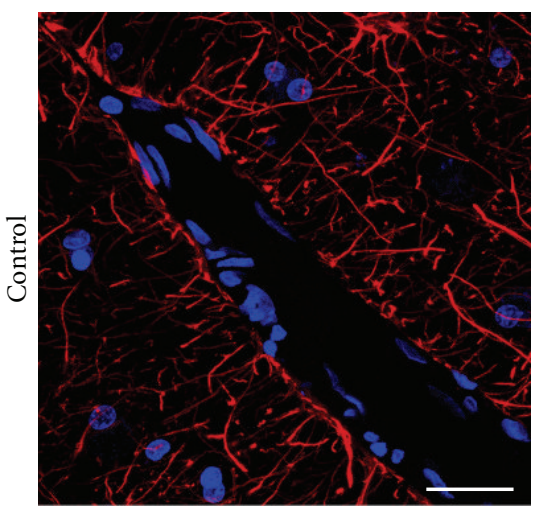

(g)

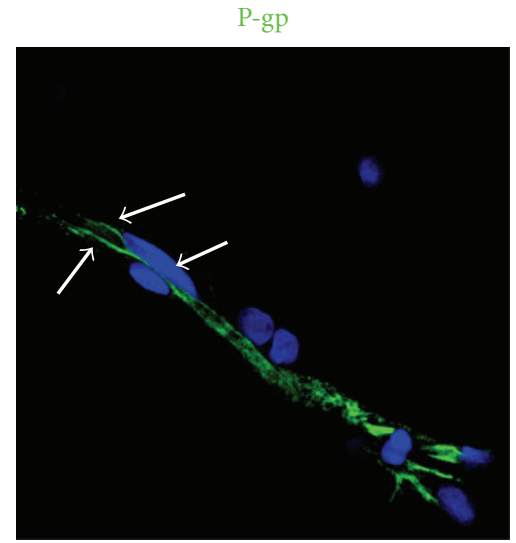

(b)

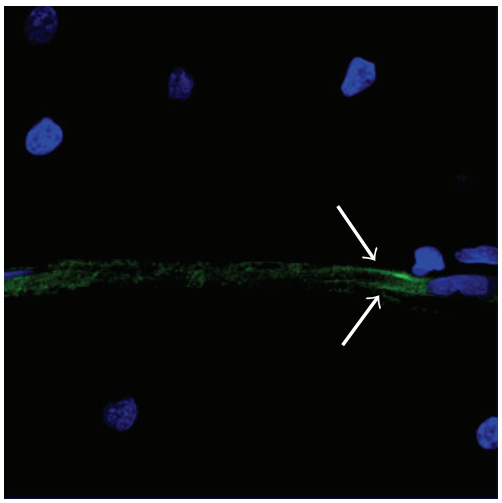

(e)

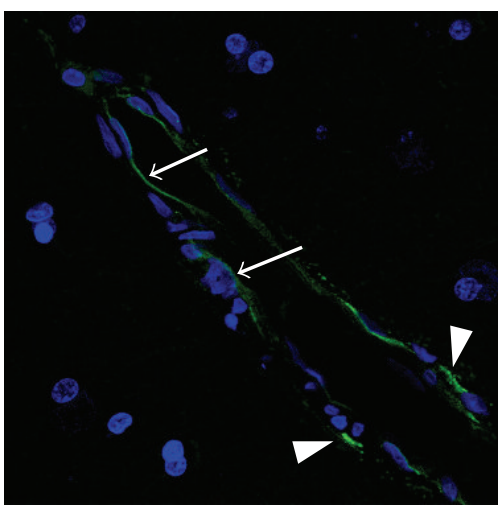

(h)

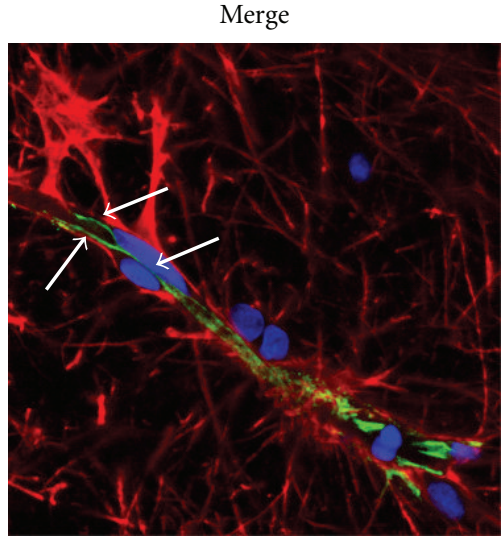

(c)

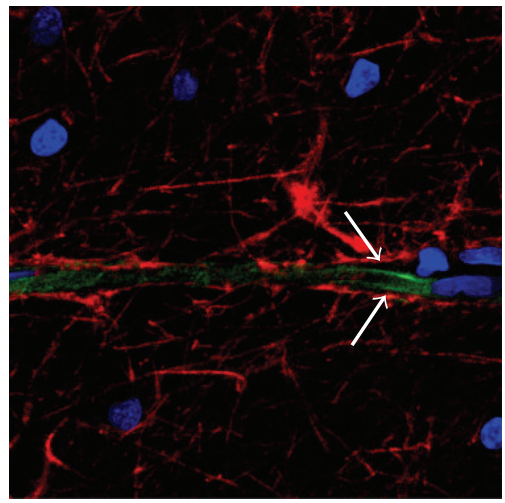

(f)

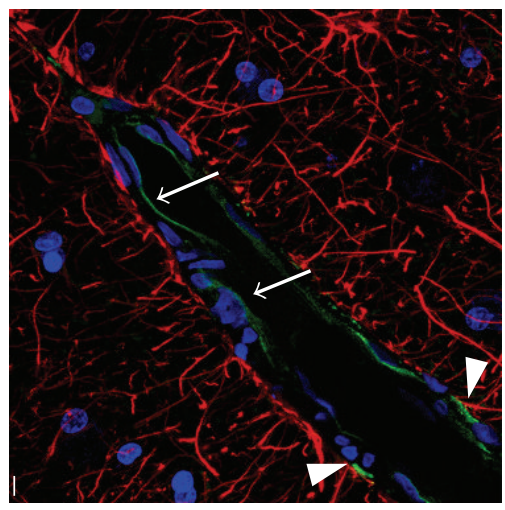

(i)

Figure 4: Laser scanning confocal microscopy of P-gp and GFAP expression in MTLE (a-c) and control (d-i) tissue sections. (a-c) High expression of P-gp which appears restricted to the luminal side of microvascular endothelial cells (b, c; arrows) and is not detectable on GFAP-positive astrocytes $(\mathrm{a}, \mathrm{c})$. A control capillary $(\mathrm{d}-\mathrm{f})$ and a small arteriole ( $\mathrm{g}-\mathrm{i}$ ) showing P-gp expression preferentially localized on the endothelial luminal front (e, f, h, i; arrows) and absence of P-gp in the GFAP-positive perivascular astrocytes (d, f, g, i). Note in (h, i) the expression of P-gp on smooth muscle cells (arrowheads). Scale bars: a-f, $10 \mu \mathrm{m}$; g-h $20 \mu \mathrm{m}$.

and controls revealed 7,862 up-regulated and 9,504 downregulated genes. These much higher numbers compared to AHE reflect enrichment of endothelial mRNA upon eliminations of glial genes from the highly purified MVEC population.

Various multidrug transporters of the ATP-binding cassette protein, subfamilies $A(A B C B)$ and $B(A B C C)$, were found to be overexpressed in AHEs and MVECs compared to the control group. A significant up-regulation of $\mathrm{ABCB} 1 / \mathrm{P}-$ gp, $\mathrm{ABCB} 2$, and $\mathrm{ABCB} 3$ was found in MVECs of epileptic hippocampi (Table 2). Among the ABCC transporters, only ABCC4 was significantly up-regulated in both AHEs and MVECs (Table 2). These data were validated by quantitative RT-PCR analysis, as summarized in Table 3. The trend 


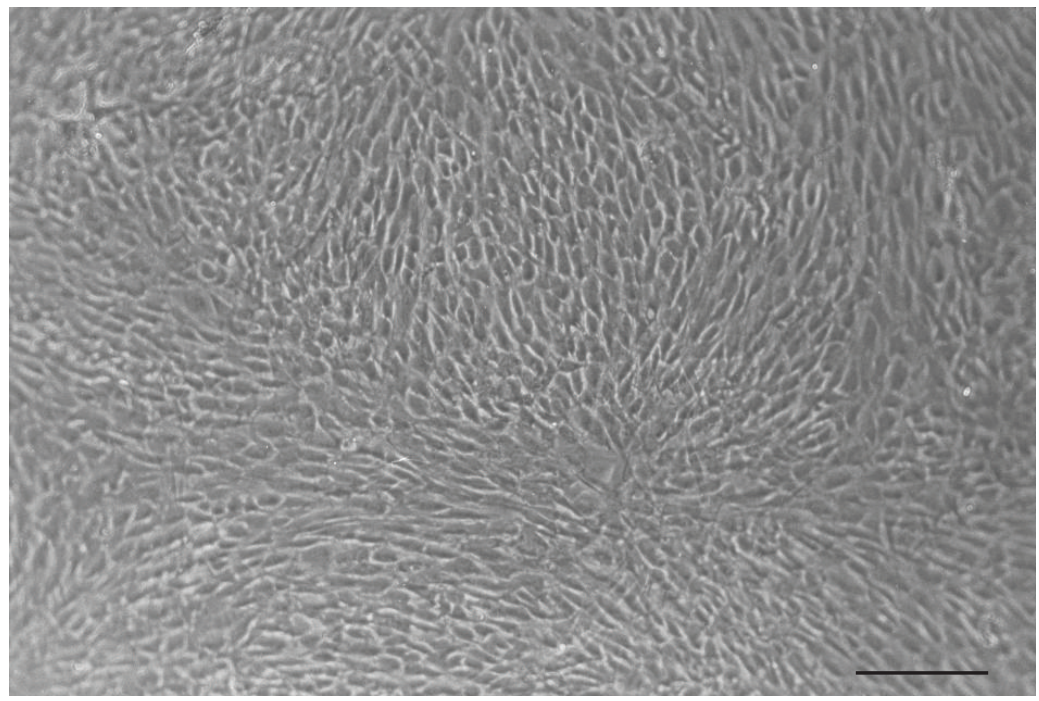

(a)
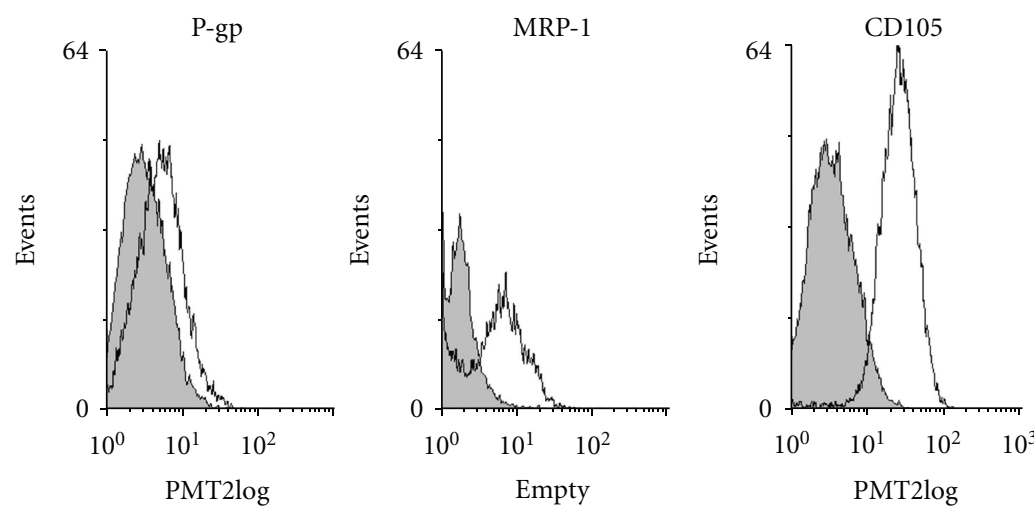

(b)
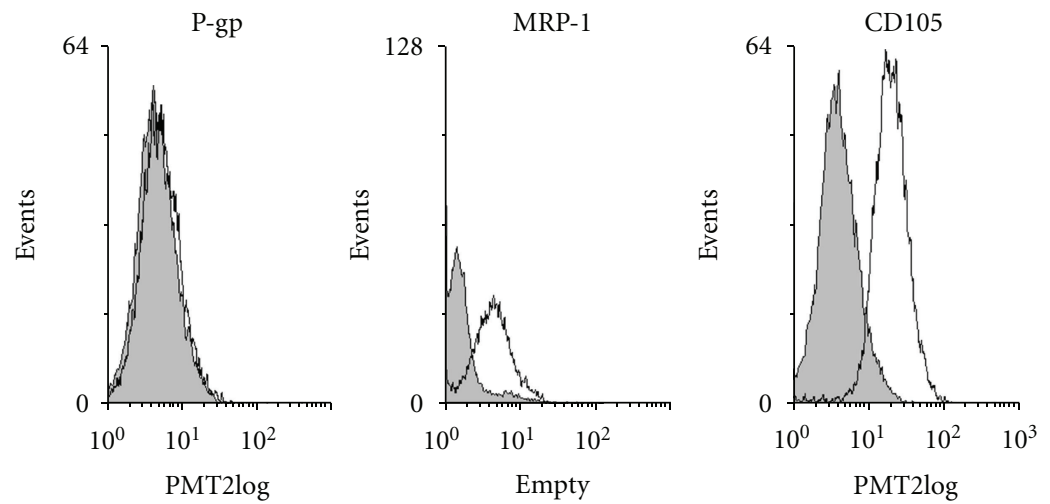

(c)

FIGURE 5: P-glycoprotein and MRP-1 expression of brain-derived microvascular endothelial cells (MVECs) of an MTLE and control patient. Morphology of primary hippocampal MVECs after 10 days in culture from an epileptic patient (a). Confluent MVECs exhibit a coblestone morphology with some spindleform-like, elongated cells. Scale bar: $60 \mu \mathrm{m}$. P-gp and MRP-1 expression was assessed by flow cytometry of primary hippocampal MVECs isolated either from a patient who underwent selective amygdalohippocampectomy (sAHE) (b) or a control tissue specimen (c). The expression of the endothelial marker endoglin (CD105) was shown to prove the purity of the MVEC cultures (b and c). The open profiles indicate the specific antibodies and the filled profiles the isotype antibodies. 
which was found by micro array analysis became statistically significant by RT-PCR for P-gp, MRP-2, and MRP4 (Table 3). As we had to deal with a large number of differentially expressed genes we evaluated those genes which were found to be highly overexpressed in epileptic patients compared to controls. Surprisingly, immunological factors such as cytokines were significantly up-regulated in AHEs $(n=8)$ compared to controls $(n=3)$. This includes proinflammatory interleukins (IL- $1 \alpha$, IL-1 $\beta$, IL-6, and IL-18), and cytokines (TNF- $\alpha$ and TGF $\beta-1$ ) as shown in Figure 2.

The immunohistochemistry staining of human hippocampal section for IL- $1 \beta$ revealed a strong expression, mainly localized at the cerebrovascular unit from epileptic hippocampus (Figures 3(c) and 3(d)), and staining for IL6 showed positive expressing cells to be evenly distributed in vessels, neurons, and glial cells of epileptic hippocampus (Figure 3 (f)).

At the protein level, high P-gp expression was found in an MTLE patient which was restricted to the luminal side of MVECs and not detectable on GFAP-positive astrocytes (Figures 4(a) and 4(c)]. In a control patient, a capillary (Figures $4(\mathrm{~d})-4(\mathrm{f})$ ) and a small arteriole (Figure $4(\mathrm{~g})$ ) were showing P-gp expression at lower level and mainly on the luminal front (Figures 4(e), 4(f), 4(h), and 4(i)).

The morphology of cultured MVECs derived from epilepsy patients had a coblestone morphology with some spindleform-like, elongated cells (Figure 5(a)) which was also seen in control MVEC cultures (data not shown) and their purity was demonstrated by expression of the endothelial marker CD105 (Figures 5(b) and 5(c)).

Interestingly cultured MVECs isolated from MTLE patients revealed by flow cytometry an enhanced P-gp expression in comparison to controls (Figures 5(b) and 5(c)). In contrast, no difference was found in their level of MRP1 expression. These data are consistent with the findings on the mRNA level.

\section{Discussion}

In our study resected hippocampi and hippocampal MVECs, forming the BBB from epileptic patients, were evaluated for their global gene expression profile. Our analysis was based on the "multitransporter up-regulation hypothesis". We also singled out those genes that were found highly up-regulated.

In examining the gene expression profile of the multidrug transporters, we included all transporters that have been described in the literature: $13 \mathrm{ABCC}$ and $12 \mathrm{ABCB}$ transporters. Some of them have been associated with medically intractable epilepsy: ABCB1/P-gp. [18-22]: MRP1 and MRP2[18-20]: MRP3 and MRP5 [19]. Most of these findings are based on IHC. However, Dombrowski et al. performed a gene expression analysis of MVEC isolated from human epileptogenic hippocampi and discovered an up-regulation of P-gp, MRP2, -3 and -5 , which is partly consistent with our findings. In addition, we observed an up-regulation of $\mathrm{ABCB} 2, \mathrm{ABCB} 3, \mathrm{ABCB} 4$, and MRP4. Until now these transporters have not been identified as being overexpressed in epileptogenic hippocampi, suggesting that of the list of gene products contributing to the "transporter hypothesis" may need to be enlarged.

With regard to the localization of these transporters, our results show an up-regulation, mainly in endothelial cells. Several studies have addressed the question of where these transporters are exactly localized; however, the answers are still highly controversial (luminal versus basolateral or even both).

At the protein level, IHC of hippocampal sections revealed that P-gp and MRP1-5 were largely confined to the endothelial cells of the hippocampus. The overexpression of these genes was validated by quantitative real-time RT-PCR, and the results were compared to that of the gene array. No significant differences were found by gene array when the averaged values of P-gp of individual epileptic patients and controls were compared. However, P-gp values obtained by RT-PCR revealed a statistically significant difference between them. The same situation was also observed by comparing the MRP4 values. This finding suggests that the RT-PCR method is more sensitive; further support for this is given by the threshold cycles (CT-values). When comparing MRP1, MRP2, and MRP3, no significant differences were obtained between the two methods. In contrast, a statistical significance for MRP5 was found by gene array analysis, but not by the RT-PCR analysis.

Unexpectedly, we observed a strong up-regulation of various cytokines (IL- $1 \alpha$, IL- $1 \beta$, IL- 6 , IL-18, TNF- $\alpha$, and TGF- $\beta 1$ ) in the hippocampus of epilepsy patients. The fact that MTLE-HS has not been considered to be an immunological disorder makes this finding even more interesting. Only few papers addressed a possible link between immunology and epilepsy, using different approaches. Two studies have been published on the gene expression profile of hippocampus in MTLE $[23,24]$. In one of the studies, the mRNA expression was compared in the hippocampi of three patients with sclerosis and three without, using a small array representing 588 genes. This study revealed 9 overexpressed genes and 12 underexpressed genes. Among these genes are those associated with gliosis (GFAP), cell death/survival, and neuronal plasticity, but none associated with inflammation [23]. In the second study, five sclerotic hippocampi from MTLE patients were analysed, using the Affymetrix GeneChip U133A [24]. Unfortunately, this study does not report on the full expression pattern in these specimens, but only the expression pattern that was also present in the hippocampi from rats having pilocarpineinduced seizures. It is important to mention that the lack of a suitable control ("healthy" hippocampus) makes it difficult to interpret these results.

With respect to the link between MTLE and immunology, one of the most remarkable findings is the role of IL$1 \beta$ in the development of febrile seizures in animal models as well as the assumption that a polymorphism of IL- $1 \beta$ at position -511 may favour a high production of IL- $1 \beta$ in patients with MTLE-HS, possibly a major trigger for the development of HS [12]. In another study, the role of cytotoxic T cells and auto-antibodies against neurons in the brain in Rassmussen encephalitis was examined suggesting an immunotherapy as a treatment approach [25]. 
In a recent article, possible pathways underlying neuronal death in HS have been postulated, including the participation of cytokines and chemokines, leading to a disturbance of the glutamatergic system, and subsequently to the persistence of seizures by chronic neuronal overexcitation $[10,26-$ 28]. Among the different factors potentially involved in the molecular pathway underlying glutamate release from astrocytes, chemokines, chemokine receptors, IL- $1 \beta$, and prostaglandin E2 have been found to be highly up-regulated in both epileptogenic hippocampus and MVEC. In experimental models and in clinical cases of epilepsy, proinflammatory and anti-inflammatory cytokines have been described in brain and plasma after seizure induction. Experimental findings demonstrated that proinflammatory cytokines IL$1 \beta$, IL-6, and TNF- $\alpha$ in microglia and astrocytes are increased and followed by a cascade of downstream inflammatory events which may recruit cells of the adaptive immune system $[29,30]$. In addition to inflammatory disease, recent evidence shows the activation of innate immune system and associated inflammatory reactions in epilepsy may modulate some of the molecular and structural changes occurring during and after seizure activity [30]. Moreover, experimental strategies aiming to block CNS or systemic inflammatory pathways reduce status epilepticus duration and seizure frequency [31].

Nevertheless, little is known about the possible underlying mechanisms which might be responsible for the fact that inflammatory factors are strongly overexpressed [32]. How inflammatory reactions intrinsic to the brain compared with those mediated by peripheral immune cells can be contributed to the epileptogenesis is poorly understood [33]. $\mathrm{BBB}$ failure might be a link between these two mechanisms.

In summary, whether these findings contribute to the persistence of seizures despite treatment with AEDs, or whether this event must be regarded as an epiphenomenon, is currently an open issue. It remains elusive, however, if such changes are causes or consequences of the disease. Since the underlying pathophysiology of MTLE-HS remains an issue of debate, more research is needed with the common goal of finding new targets and therapeutic strategies. The findings that inflammatory mediators contribute to the onset and recurrence of seizures in experimental models, as well as the presence of inflammatory molecules in human epileptogenic tissue, do highlight the possibility of targeting specific inflammation-related pathways to control seizures that are otherwise resistant to the available AEDs. Drugs that block IL- $1 \beta$ actions have entered clinical trials as potential therapeutics for autoimmune and inflammatory pathologies and may also have therapeutic potential in refractory epilepsies associated with proinflammatory processes in the brain [34].

\section{Acknowledgments}

This work was supported by the National Center of Competence in Research (NCCR, Neural Plasticity and Repair) and The Olga Mayenfisch Foundation. The authors are very thankful for the group of Dr. R. Schlapbach (Functional
Genomics Center Zurich, University of Zurich) for their excellent advice and help on transcriptomics technology, respectively. S. Muljana and M. Haas are acknowledged for technical assistance.

\section{References}

[1] H. G. Wieser, M. Ortega, A. Friedman, and Y. Yonekawa, "Long-term seizure outcomes following amygdalohippocampectomy," Journal of Neurosurgery, vol. 98, no. 4, pp. 751-763, 2003.

[2] H. G. Wieser, "Mesial temporal lobe epilepsy with hippocampal sclerosis," Epilepsia, vol. 45, no. 6, pp. 695-714, 2004.

[3] W. Löscher, "Mechanism of drug resistance," Epileptic Disorders, vol. 1, pp. 3-9, 2008.

[4] G. Regesta and P. Tanganelli, "Clinical aspects and biological bases of drug-resistant epilepsies," Epilepsy Research, vol. 34, no. 2-3, pp. 109-122, 1999.

[5] D. Schmidt and W. Löscher, "Drug resistance in epilepsy: putative neurobiologic and clinical mechanisms," Epilepsia, vol. 46, no. 6, pp. 858-877, 2005.

[6] L. J. Stephen, P. Kwan, and M. J. Brodie, "Does the cause of localisation-related epilepsy influence the response to antiepileptic drug treatment?" Epilepsia, vol. 42, no. 3, pp. 357-362, 2001.

[7] E. Oby and D. Janigro, "The blood-brain barrier and epilepsy," Epilepsia, vol. 47, no. 11, pp. 1761-1774, 2006.

[8] N. C. de Lanerolle and T. S. Lee, "New facets of the neuropathology and molecular profile of human temporal lobe epilepsy," Epilepsy and Behavior, vol. 7, no. 2, pp. 190203, 2005.

[9] J. L. Jankowsky and P. H. Patterson, "The role of cytokines and growth factors in seizures and their sequelae," Progress in Neurobiology, vol. 63, no. 2, pp. 125-149, 2001.

[10] A. Vezzani, D. Moneta, C. Richichi, C. Perego, and M. G. De Simoni, "Functional role of proinflammatory and antiinflammatory cytokines in seizures," Advances in Experimental Medicine and Biology, vol. 548, pp. 123-133, 2004.

[11] S. F. Berkovic and G. D. Jackson, "The hippocampal sclerosis whodunit: enter the genes," Annals of Neurology, vol. 47, no. 5, pp. 557-558, 2000.

[12] K. Kanemoto, J. Kawasaki, T. Miyamoto, H. Obayashi, and M. Nishimura, "Interleukin (IL)- $1 \beta$, IL- $1 \alpha$, and IL- 1 receptor antagonist gene polymorphisms in patients with temporal lobe epilepsy," Annals of Neurology, vol. 47, no. 5, pp. 571-574, 2000.

[13] C. Dubé, A. Vezzani, M. Behrens, T. Bartfai, and T. Z. Baram, "Interleukin- $1 \beta$ contributes to the generation of experimental febrile seizures," Annals of Neurology, vol. 57, no. 1, pp. 152155, 2005.

[14] W. M. Pardridge, J. Eisenberg, and T. Yamada, "Rapid sequestration and degradation of somatostatin analogues by isolated brain microvessels," Journal of Neurochemistry, vol. 44, no. 4, pp. 1178-1184, 1985.

[15] L. A. Repesh and T. J. Fitzgerald, "Interactions of tumor cells with intact capillaries: a model for intravasation," Clinical and Experimental Metastasis, vol. 2, no. 2, pp. 139-150, 1984.

[16] E. Hubbell, W. M. Liu, and R. Mei, "Robust estimators for expression analysis," Bioinformatics, vol. 18, no. 12, pp. 15851592, 2002. 
[17] T. Langmann, R. Mauerer, and G. Schmitz, "Human ATPbinding cassette transporter TaqMan low-density array: analysis of macrophage differentiation and foam cell formation," Clinical Chemistry, vol. 52, no. 2, pp. 310-313, 2006.

[18] E. Aronica, J. A. Gorter, G. H. Jansen et al., "Expression and cellular distribution of multidrug transporter proteins in two major causes of medically intractable epilepsy: focal cortical dysplasia and glioneuronal tumors," Neuroscience, vol. 118, no. 2, pp. 417-429, 2003.

[19] S. M. Dombrowski, S. Y. Desai, M. Marroni et al., "Overexpression of multiple drug resistance genes in endothelial cells from patients with refractory epilepsy," Epilepsia, vol. 42, no. 12, pp. 1501-1506, 2001.

[20] H. Kubota, H. Ishihara, T. Langmann et al., "Distribution and functional activity of P-glycoprotein and multidrug resistanceassociated proteins in human brain microvascular endothelial cells in hippocampal sclerosis," Epilepsy Research, vol. 68, no. 3, pp. 213-228, 2006.

[21] S. M. Sisodiya, "Mechanisms of antiepileptic drug resistance," Current Opinion in Neurology, vol. 16, no. 2, pp. 197-201, 2003.

[22] D. M. Tishler, K. I. Weinberg, D. R. Hinton, N. Barbaro, G. M. Annett, and C. Raffel, "MDR1 gene expression in brain of patients with medically intractable epilepsy," Epilepsia, vol. 36, no. 1, pp. 1-6, 1995.

[23] A. J. Becker, J. Chen, S. Paus et al., "Transcriptional profiling in human epilepsy: expression array and single cell real-time qRT-PCR analysis reveal distinct cellular gene regulation," NeuroReport, vol. 13, no. 10, pp. 1327-1333, 2002.

[24] A. J. Becker, J. Chen, A. Zien et al., "Correlated stage- and subfield-associated hippocampal gene expression patterns in experimental and human temporal lobe epilepsy," European Journal of Neuroscience, vol. 18, no. 10, pp. 2792-2802, 2003.

[25] C. G. Bien, U. Gleissner, R. Sassen, G. Widman, H. Urbach, and C. E. Elger, "An open study of tacrolimus therapy in Rasmussen encephalitis," Neurology, vol. 62, no. 11, pp. 21062109, 2004.

[26] T. Ravizza, B. Gagliardi, F. Noé, K. Boer, E. Aronica, and A. Vezzani, "Innate and adaptive immunity during epileptogenesis and spontaneous seizures: evidence from experimental models and human temporal lobe epilepsy," Neurobiology of Disease, vol. 29, no. 1, pp. 142-160, 2008.

[27] A. Vezzani and T. Z. Baram, "New roles for interleukin- $1 \beta$ in the mechanisms of epilepsy," Epilepsy Currents, vol. 4, pp. 45$50,2007$.

[28] A. Vezzani, S. Balosso, and T. Ravizza, "The role of cytokines in the pathophysiology of epilepsy," Brain, Behavior, and Immunity, vol. 22, no. 6, pp. 797-803, 2008.

[29] M. D. Nguyen, J. P. Julien, and S. Rivest, "Innate immunity: the missing link in neuroprotection and neurodegeneration?" Nature Reviews Neuroscience, vol. 3, no. 3, pp. 216-227, 2002.

[30] A. Vezzani and T. Granata, "Brain inflammation in epilepsy: experimental and clinical evidence," Epilepsia, vol. 46, no. 11, pp. 1724-1743, 2005.

[31] E. A. Van Vliet, S. D. C. Araújo, S. Redeker, R. Van Schaik, E. Aronica, and J. A. Gorter, "Blood-brain barrier leakage may lead to progression of temporal lobe epilepsy," Brain, vol. 130, no. 2, pp. 521-534, 2007.

[32] S. Bauer, S. Cepok, A. Todorova-Rudolph et al., "Etiology and site of temporal lobe epilepsy influence postictal cytokine release," Epilepsy Research, vol. 86, no. 1, pp. 82-88, 2009.

[33] A. Vezzani and D. Janigro, "Leukocyte-endothelial adhesion mechanism in epilepsy: cheers and jeers," Epilepsy Currents, vol. 9, pp. 118-221, 2009.
[34] A. Vezzani, S. Balosso, M. Maroso, D. Zardoni, F. Noé, and T. Ravizza, "ICE/caspase 1 inhibitors and IL- $1 \beta$ receptor antagonists as potential therapeutics in epilepsy," Current Opinion in Investigational Drugs, vol. 11, no. 1, pp. 43-50, 2010. 


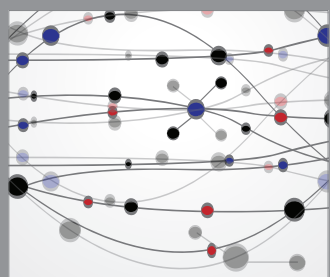

The Scientific World Journal
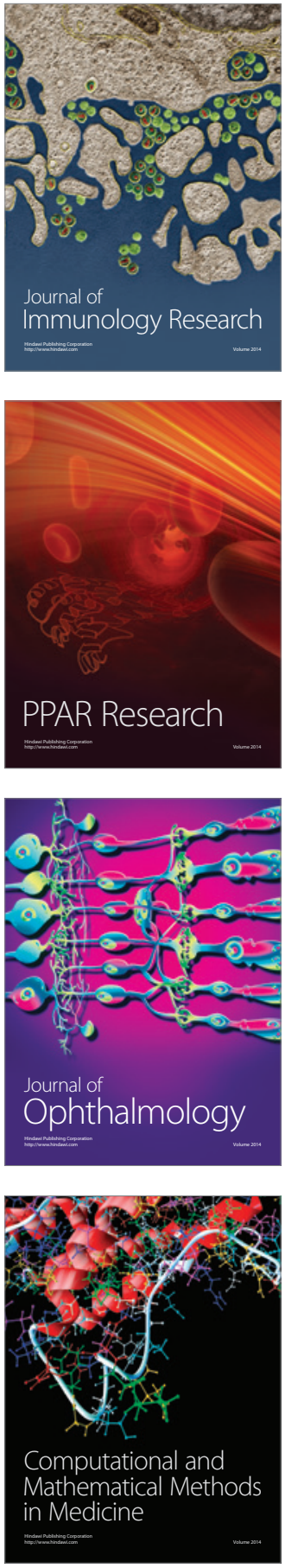

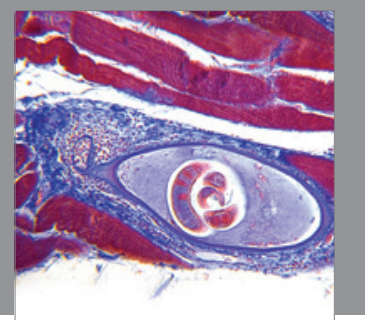

Gastroenterology

Research and Practice
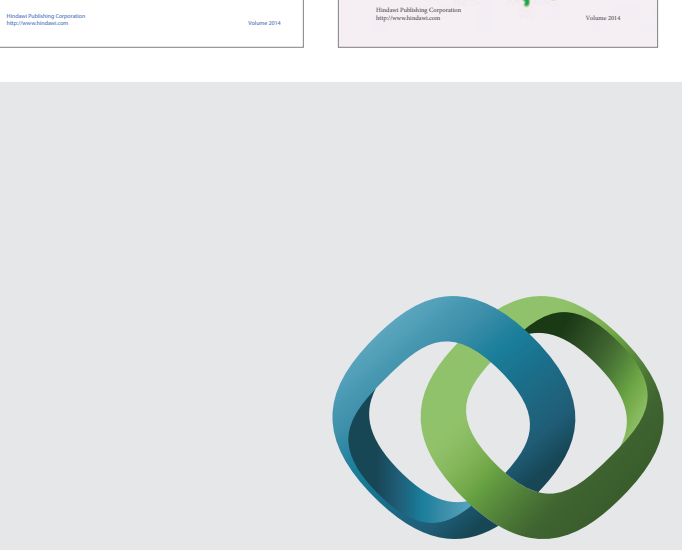

\section{Hindawi}

Submit your manuscripts at

http://www.hindawi.com
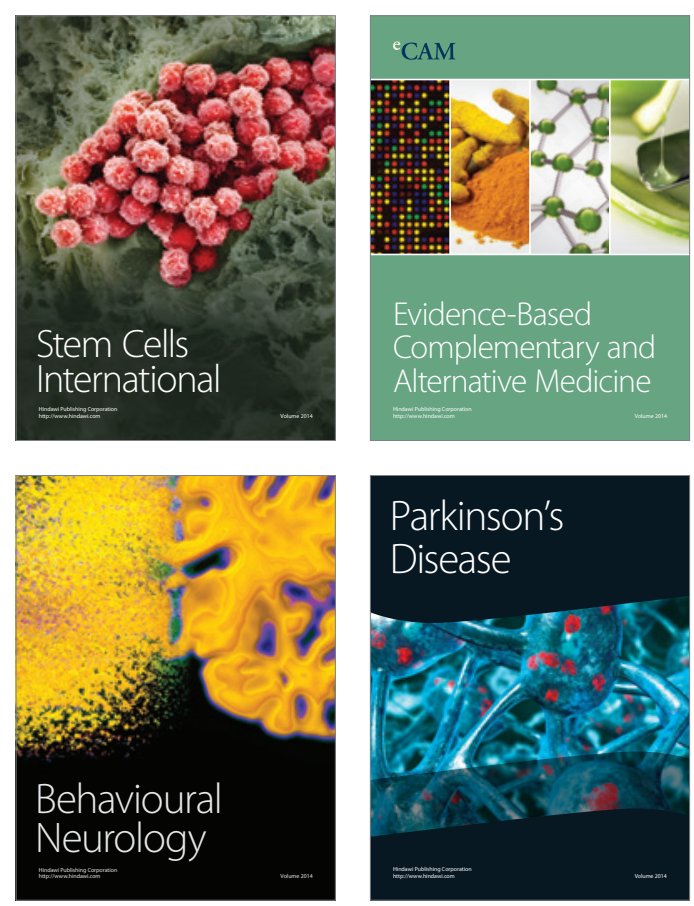

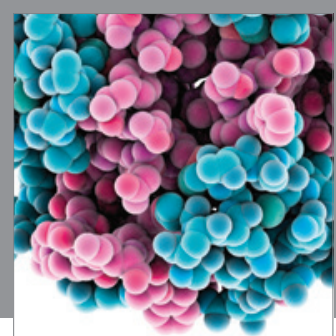

Journal of
Diabetes Research

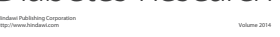

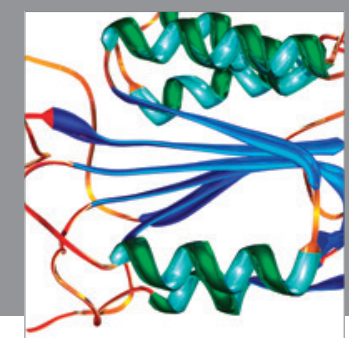

Disease Markers
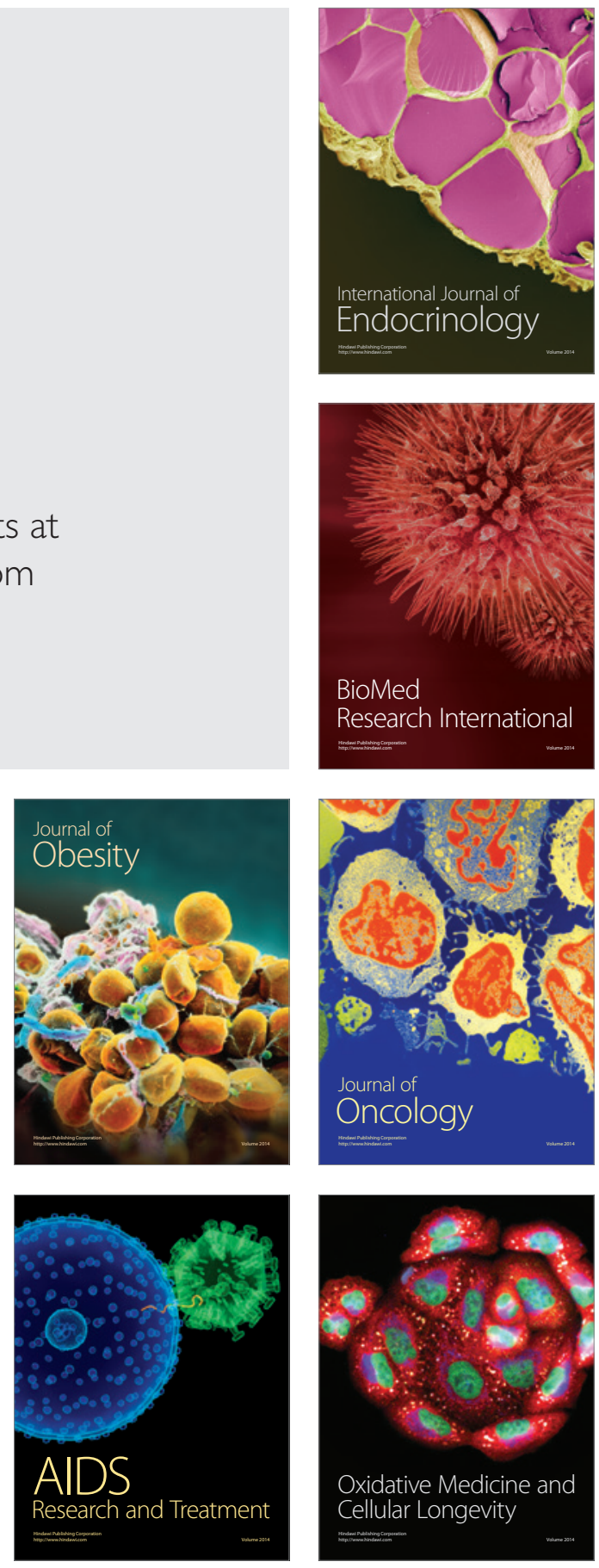